\title{
A Relação entre a Geração de Valor Econômico e o Valor de Mercado das
} Empresas Sucroalcooleiras Brasileiras

\section{The Relationship between Economic Value and Market Value of the Brazilian Sugar and Alcohol Companies}

\section{Melise Alessandra Sobue}

Guaduada em Administração pela Universidade de São Paulo

Endereço: Av. Bandeirantes, 3900 - Monte Alegre

CEP: 14040-900 - Ribeirão Preto/SP - Brasil

E-mail: me.alessandra@hotmail.com

Telefone: (16) 8119-6070

\section{Tabajara Pimenta Junior}

Doutor em Administração pela Universidade de São Paulo

Endereço: Av. Bandeirantes, 3900 - Monte Alegre

CEP: 14040-900 - Ribeirão Preto/SP - Brasil

E-mail: taba.jr@terra.com.br

Telefone: (16) 8119-6070

Artigo recebido em 14/02/2012. Revisado por pares em 24/04/2012. Reformulado em 23/05/2012. Recomendado para publicação em 15/06/2012 por Sandra Rolim Ensslin (Editora Científica). Publicado em 28/06/2012. 


\title{
Resumo
}

Este trabalho aborda a criação de valor por empresas de capital aberto do setor sucroalcooleiro brasileiro, medida pelo EVA e pelo MVA. Foram analisados a existência e o nível de correlação entre os EVAs gerados por empresas sucroalcooleiras (São Martinho, Cosan, Cosan Limited e Guarani) e os respectivos MVAs alcançados no mercado. Os resultados obtidos revelaram uma correlação estatisticamente significativa, ao nível de 5\%, apenas para a Cosan Limited. Não foram detectadas correlações significativas para três das quatro empresas analisadas. Concluímos que o EVA não é uma medida consistente para sinalizar o comportamento futuro do MVA das empresas.

Palavras-chave: EVA. MVA. Valor econômico. Setor sucroalcooleiro.

\begin{abstract}
This paper is about creating value for Brazilian sugar and alcohol companies, as measured by EVA and MVA. We analyze the existence and the level of correlation between the EVA generated by sugar and alcohol companies (São Martinho, Cosan, Cosan Limited and Guarani), and their MVAs reached the market. The results showed the existence of correlation, statistically significant level of 5\%, only to Cosan Limited. There is no significant correlation for three of the four companies examined. We conclude that EVA is not a consistent measure to signal the future behavior of the MVA of the companies
\end{abstract}

Keywords: EVA. MVA. Economic value. Sugar and ethanol business.

\section{Introdução}

O valor de mercado e o valor econômico de uma empresa são determinantes como balizadores para as transações com seus títulos (de dívida e propriedade) no mercado de capitais. Maximizar o valor da empresa é um objetivo comum a todas as administrações nas últimas décadas mais do que no passado. Segundo Stewart (1995), a busca do valor direciona recursos escassos para um uso mais racional e para usuários mais produtivos. Quanto maior a eficácia no uso e no gerenciamento de recursos, mais fortes serão o crescimento econômico e a taxa de melhoria no padrão de vida das pessoas.

O desafio de se administrar organizações cada vez maiores e mais globalizadas, com foco na agregação de valor e consequente geração de riqueza para os financiadores, tem sido tema de muitos estudos em todo o mundo. O desempenho econômico é medido pela capacidade de gerar valor adicional, a cada período, ao capital dos acionistas. Essa medida é denominada Economic Value Added - EVA (Valor Econômico Adicionado).

Em princípio, a capacidade de gerar EVA deveria se refletir no valor de mercado da empresa. O valor presente dos EVAs futuros deveria corresponder ao chamado Market Value Added - MVA (Valor de Mercado Adicionado). O preço das ações da empresa no mercado deveria compor o valor do seu capital investido com uma parcela adicional que refletisse a capacidade de geração de valor adicional. Ou seja, para uma empresa agregadora de valor, os 
preços das ações no mercado são superiores àqueles que refletiriam apenas o valor do capital investido. A parcela adicional é o MVA e ela reflete a geração dos EVAs futuros. Como o adicional de riqueza pertence aos acionistas, quando o capital investido por eles é igual ao valor de livro (PL contábil), é dito que o MVA é o quanto o mercado atribui de valor à empresa além do seu valor de livro.

A análise do desempenho econômico das empresas é especialmente importante para alguns setores da economia brasileira, dada sua relevância na composição do PIB, na pauta de exportações e na matriz energética do país. É o caso do setor sucroalcooleiro. Atualmente, países dos cinco continentes estão procurando aumentar a produção e/ou o uso de biocombustíveis. O etanol é uma das principais fontes de energia renovável. E as iniciativas e os projetos de produção de energia estão balizados, cada vez mais, por preocupações com o meio ambiente e a sustentabilidade. Quanto ao consumo mundial de açúcar, a previsão é de um aumento consistente ao longo do tempo, devido, entre outras razões, ao crescimento da população mundial, aumento do poder de compra dos consumidores e da explosão do consumo de alimentos processados em todo o mundo resultante da migração da população rural para as áreas urbanas em regiões como a Ásia (COSAN, 2009).

Outro aspecto importante diz respeito à segurança energética, um dos principais desafios deste século. $\mathrm{O}$ aumento da população mundial e do consumo per capita, associados ao problema da mudança do clima, ensejam a necessidade de ações mais coordenadas e sustentáveis em seus aspectos ambientais, sociais e econômicos. Nesse sentido, o Brasil tem muito a contribuir, pois possui uma matriz energética com $46 \%$ de fontes renováveis num mundo que só utiliza $15 \%$ em média. Isso faz com que o País possua uma posição de destaque no cenário mundial, principalmente por sua forte estratégia em agroenergia, que representa mais da metade dessa fonte renovável (MAPA, 2009).

As empresas da cadeia sucroalcooleira devem, nesse cenário de relevância estratégica e destacado potencial de crescimento do setor, mostrar competência em ter um bom desempenho econômico. Esse é um fator fundamental para garantir o influxo de capitais necessários aos investimentos, atraídos por retornos compatíveis com os níveis de risco inerentes à atividade agrícola. $\mathrm{O}$ conjunto de provedores de capital não está mais restrito, como no passado, aos próprios produtores rurais e às agências de fomento governamentais. $\mathrm{O}$ País conta hoje com grandes empresas, projetos de larga escala, parcerias internacionais e administrações competentes, que exploram as possibilidades de captações no mercado de capitais por meio da emissão de títulos de dívida e propriedade. Volumes expressivos de recursos fluem de quaisquer partes do mundo em busca de oportunidades de investimentos promissores.

O mercado de capitais é um meio e, ao mesmo tempo, uma vitrine aos olhos dos investidores globalizados. Empresas ali expostas pelo reflexo de seu desempenho econômico alcançam recursos que antes eram inexploráveis ou inalcançáveis para viabilizar suas iniciativas. Empresas realmente capazes de agregar valor e de gerar riquezas veem seus papéis sendo disputados e valorizados. Se elas têm um desempenho consistente no tempo, o valor adicionado pelo mercado aos seus níveis de capital investido (MVA) devem refletir adequadamente essa competência em gerar valor.

Esse é o questionamento que motivou este estudo. A pergunta que pretendemos responder é: Há uma relação empírica entre a geração de EVA e nível de MVA alcançado pelas empresas brasileiras de capital aberto do setor sucroalcooleiro? Para esse fim estabelecemos o objetivo de calcular a geração de EVA e de MVA ao longo dos doze 
trimestres compreendidos entre setembro de 2007 e junho de 2010, para quatro das cinco empresas do setor sucroalcooleiro listadas na BM\&FBovespa (uma delas não foi incluída no estudo por apresentar liquidez extremamente baixa) e mensurar a correlação existente entre essas duas medidas de desempenho econômico.

\title{
2 Referencial Teórico
}

De maneira diferente do que se propõem os indicadores clássicos de desempenho financeiro, o MVA e o EVA são dois tipos de indicadores de desempenho econômico que fornecem bons parâmetros sobre os quais a alta administração e os investidores podem se basear para tomar conhecimento da evolução do valor econômico da organização. Segundo Santos e Watanabe (2005), o economista Alfred Marshall, em 1890, já havia escrito: "O que resta de seus lucros [do proprietário ao administrador] após a dedução dos juros sobre seu capital à taxa em vigor pode ser considerado como uma remuneração pela realização da administração".

O EVA é uma medida de lucro econômico que, segundo Stewart III (2005), subtrai o custo de capital dos lucros operacionais gerados em um empreendimento. Para esse pesquisador, a área operacional pode tomar inúmeras iniciativas individuais para criar valor de mercado (financeiro/econômico), mas todas elas devem em algum momento cair em uma das três categorias medidas pelo EVA: se os lucros operacionais puderem ser incrementados sem que seja inserido qualquer outro capital; se outro capital for investido em quaisquer projetos que produzem mais do que o custo total de capital; e se o capital for desviado ou retirado de atividades negociáveis que não cubram seus próprios custos de capital.

O lucro econômico, segundo Copeland, Koller e Murrin (2002), traduz dois tipos de vetores de valor em um único valor monetário: o retorno sobre capital investido e o crescimento. Este último está relacionado ao volume de capital investido ou ao porte da empresa. Muitas vezes, as empresas se concentram em tamanho (medido, frequentemente, pelos lucros) ou em retorno. Concentrar-se no tamanho (por exemplo, lucros ou crescimento dos lucros) pode destruir valor se os retornos sobre o capital forem muito baixos. Da mesma forma, perceber retorno elevado sobre uma base de capital pequena pode representar perda de oportunidades.

Copeland, Koller e Murrin (2002) ainda esclarecem que o que se deve considerar como capital investido na empresa é o valor, que exige remuneração financeira explícita, investido nos ativos operacionais, ou seja, nas operações da empresa.

Na definição de Stewart (2005, p. 615), o MVA é definido como sendo:

\begin{abstract}
A diferença entre o valor de mercado de uma empresa e seu capital empregado, o MVA é a medida do valor que uma empresa criou em excesso, sobre recursos já comprometidos com o empreendimento. Em tese, o MVA representa o valor presente liquido de todos os projetos de investimento de capital passados e projetados.
\end{abstract}

O valor de mercado é obtido pela multiplicação do preço corrente das ações de uma empresa pela quantidade de ações que essa empresa possui.

Para Ehrbar (1999), o MVA tem a proposta de mensurar a riqueza gerada por um empreendimento, em termos de percepção do mercado. Para Young e O’byrne (2003), uma das maiores vantagens do EVA é proporcionar uma ligação entre uma medida interna de 
desempenho e a avaliação feita pelo mercado de capitais, certificando as empresas que o utilizam de que o esforço gerencial para melhorar esse indicador será avaliado e recompensado de forma consistente com a moderna teoria de finanças corporativas. Ehrbar (1999) ainda aponta que o MVA em si não tem muita utilidade como parâmetro para auxiliar os gestores na tomada de decisão cotidiana. Isso acontece devido ao fato de o indicador só poder ser calculado se a empresa tiver ações listadas em alguma bolsa de valores, tendo um preço de mercado. Outra limitação é que o MVA só pode ser calculado em níveis agregados, não podendo ser discriminado para unidades de negócio ou empresas subsidiárias. Dessa forma, os gerentes devem focar uma medida interna de desempenho que seja estreitamente ligada ao parecer externo do MVA. Essa medida seria o EVA.

A ideia de uma organização voltada ao valor torna a empresa mais atraente, não somente para os investidores, mas também para empregados, clientes e outros grupos que mantêm interesse na empresa. À medida que as organizações buscam alinhar suas políticas e estratégias com um objetivo de longo prazo de gerar valor para o acionista, surgem novos desafios a ser enfrentados.

\subsection{Revisão de Estudos Publicados}

Turvey et al., (2000), pesquisadores da Universidade de Guelph, no Canadá, estudaram a relação entre a geração de EVA e o desempenho do mercado acionário de 17 empresas de capital aberto do setor canadense de agronegócio. Para avaliarem a viabilidade/superioridade dessa medida de desempenho econômico, o EVA foi comparado com outras medidas tradicionais de desempenho, como o ROA (Retorno sobre Ativos), ROE (Retorno sobre o Patrimônio Líquido) e ROS (Retorno sobre Vendas), calculadas para os exercícios dos anos de 1994 a 1998. As variáveis de desempenho foram relacionadas aos retornos, oferecidos pelas cotações das ações das empresas com o uso de regressões lineares.

Pela análise dos resultados, os pesquisadores observaram que apenas cinco das 17 empresas pesquisadas tinham retornos maiores do que os retornos do mercado, no entanto vieram à custa de riscos elevados, de até cinco vezes o risco de mercado. Outro resultado da pesquisa foi que a relação entre preço da ação e o EVA não se mostrou estável e que havia pouca correspondência com o valor da empresa, o risco ou o retorno. Ou seja, a geração de EVA não era sistematicamente precificada pelo mercado. Também não houve indícios de que empresas com maiores níveis de geração de EVA tinham maior desempenho nos três tipos de retorno (ROA, ROE e ROS).

Baum, Sarver e Strickland (2004), pesquisadores da Universidade do Tenessee, nos EUA, analisaram o relacionamento entre o desempenho da empresa, medido pela geração de EVA e MVA, e a remuneração do Chief Executive Officer (CEO). O estudo também considerou se o relacionamento entre remuneração e desempenho variava de acordo com os tipos de indústria. Foram analisados dados de remuneração dos CEOs de 355 companhias. A remuneração incluía salários, bônus e ganhos de opções realizadas ou não. Os resultados da pesquisa, obtidos com a aplicação de regressões lineares, mostraram uma associação positiva e significante do MVA com cada variável da compensação do CEO, mas nenhuma relação estatisticamente significativa do EVA com a remuneração dos executivos.

Ferguson, Rentzler e Yu (2006) estudaram se a geração de EVA e MVA poderia ser usada como uma boa referência para o desempenho futuro das empresas. O estudo buscou avaliar se organizações com elevados valores de MVA e forte geração de EVA tinham ações 
que ofereciam retornos superiores e apresentavam melhor performance financeira futura. Foram analisadas 1.000 companhias com os maiores MVA em todo o mundo, segundo o ranking produzido pela Stern e STEWART III \& Co, referente ao período entre 1993 e 2002. Analisando o nível relativo de MVA e EVA, os pesquisadores procuraram determinar qual dessas medidas gerou predições mais consistentes da performance do mercado de ações. Foram formados dez grupos com 100 empresas cada e um ranking com eles. Indiferente da escolha da variável do ranking (MVA ou EVA), o risco ajustado para o grupo ganhador foi maior do que o do grupo perdedor. Entretanto, os retornos obtidos não eram significativamente diferentes. A conclusão foi que a geração de EVA e MVA não podia ser considerada uma boa indicação de melhor desempenho futuro relativo.

Mittal, Sinha e Singh (2008) se propuseram a estudar se havia alguma relação entre Responsabilidade Social Corporativa (CSR) e o desempenho das empresas indianas que a adotavam. Para esta pesquisa foram utilizados três diferentes indicadores: dois de desempenho econômico (MVA e EVA) e um de responsabilidade social (possuir um código de ética). A amostra consistiu de 50 companhias advindas do $S \& P C N X$ Nifty, principal índice acionário da Índia, para os anos de 2001 a 2005. As empresas foram divididas em dois grupos: o primeiro, com aquelas que possuíam códigos de ética/condutas/princípios listados em seus relatórios anuais; e o segundo, com aquelas que não tinham.

Os resultados mostraram que o CSR apresentou uma relação positiva e estatisticamente significativa com o MVA das empresas, mas uma relação negativa com o EVA. A conclusão principal dos pesquisadores foi que o aumento do valor das empresas não dependia da existência de Responsabilidade Social, mas meramente da percepção dos investidores sobre a companhia no tocante ao tema.

Mandilas et al., (2009) estudaram o poder explicativo de medidas de valor baseadas em performance (EVA) e outros três tipos de medidas contábeis tradicionais: EPS (lucro por ação); ROI (retorno sobre investimentos) e ROE (retorno sobre patrimônio líquido) com empresas do mercado atuantes na Grécia. Foram analisadas as empresas listadas na Bolsa de Valores de Atenas entre 1996 e 2005. Este artigo visou descobrir quais medidas melhor explicavam os retornos do mercado grego de ações, além de explorar se a combinação de duas diferentes medidas ao invés de uma única fornece melhor informação sobre os retornos das ações.

No estudo foram feitas duas investigações: a primeira examinou qual medida (EPS, ROI, ROE ou EVA) melhor explicava os retornos oferecidos pelas variações nas cotações das ações das empresas, no período analisado; a segunda examinou se a geração de EVA adicionou informação quando combinada com outras medidas tradicionais (EPS, ROI ou ROE) para melhor explicar o comportamento do retorno das ações. Os resultados revelaram que o poder de explicação dos retornos era decrescente para os indicadores EPS, EVA, ROI e ROE, nessa ordem, e que a combinação do EVA com outras medidas não contribuiu significativamente para o aumento do poder de explicação.

Outro estudo, mais recente, que também explorou a questão do poder informacional dos indicadores contábeis convencionais em comparação com medidas de desempenho econômico como o EVA, foi o de Kumar e Sharma (2011). No estudo, foram analisados dados de 873 empresas de capital aberto na Índia, referentes ao período que abrange os anos de 2000 a 2008. Os resultados revelaram que o EVA não se mostrou uma variável superior para explicar o comportamento do valor das empresas, mas se mostrou capaz de contribuir, combinado com outros indicadores contábeis para aumentar esse poder de explicação. 
No Brasil, alguns estudos foram publicados sobre esse tema, como os de Saurin, Mussi e Cordioli (2000); Silveira, Okimura e Sousa (2004); Ferreira e Lopes (2005); Santos e Watanabe (2005); Cerqueira, Soares e David (2009); e, mais recentemente, Coscarelli, Lamounier e Amaral (2011).

Saurin, Mussi e Cordioli (2000) avaliaram o desempenho econômico de empresas estatais privatizadas no Brasil no período de 1991 a 1997, com base no EVA e no MVA, além de buscarem identificar se havia correlação entre esses indicadores no período analisado. A amostra foi composta por todas as empresas estatais que foram privatizadas nesse período. A análise consistiu na comparação dos valores de MVA e EVA alcançados nos períodos anterior e posterior à privatização. Os resultados mostraram que a expectativa de que as empresas privatizadas apresentariam melhorias em suas condições econômico-financeiras, refletidas na lucratividade e rentabilidade, não se confirmou.

Silveira, Okimura e Sousa (2004) testaram duas diferentes métricas para descobrir qual delas estaria mais associada ao retorno das ações no mercado, isto é, qual das métricas explicaria melhor o desempenho das ações. Em linhas gerais, existem métricas relacionadas ao lucro residual, que levam em consideração o custo de oportunidade de todos os fornecedores de recursos das empresas, e métricas relacionadas ao lucro contábil, que utilizam o lucro indicado na demonstração de resultados oficial da companhia comparando-o aos seus ativos, patrimônio líquido ou receitas. O valor econômico adicionado (EVA) é uma das métricas de lucro residual mais utilizada, enquanto que o lucro líquido é a principal medida de lucro contábil. Os pesquisadores procuraram testar a associação de três métricas - EVA, lucro líquido e fluxo de caixa operacional - com o comportamento do retorno das ações das companhias abertas brasileiras. No estudo, havia a expectativa de que o EVA seria capaz de fornecer um conteúdo informacional maior do que o lucro líquido e o fluxo de caixa operacional em relação ao retorno de mercado das ações.

Dados de 109 companhias abertas brasileiras, não financeiras, e com ações de elevada liquidez, foram tratados em painel para o período entre os anos de 1997 a 2003 . Foram obtidas evidências em favor da hipótese de pesquisa de que, de fato, o EVA é uma medida superior ao lucro líquido e ao fluxo de caixa operacional na associação com o retorno das ações. Uma implicação importante dos resultados é que medidas de desempenho que levam em conta o custo de oportunidade dos recursos investidos na companhia forneceram uma melhor predição do retorno das ações do que as métricas baseadas exclusivamente em dados contábeis.

Ferreira e Lopes (2005), em um estudo com uma proposta semelhante ao de Silveira, Okimura e Sousa (2004), testaram se a geração de EVA apresenta maior relação com o retorno das ações do que as medidas baseadas apenas em dados contábeis, como ROE e FCF (Fluxo de Caixa Livre). Mas os resultados revelaram que nenhuma das métricas avaliadas foi eficiente na predição do comportamento dos retornos oferecidos pelas variações nas cotações das ações de empresas listadas no mercado de capitais brasileiro.

Santos e Watanabe (2005) procuraram averiguar se, no caso das empresas brasileiras, a forte correlação entre MVA e EVA, detectada por Stewart (2005) para as empresas norteamericanas, também se verificava. A pesquisa foi baseada em uma amostra formada por empresas de capital aberto cujas ações foram negociadas na BM\&FBovespa durante o período de 1996 a 2001. Os resultados apresentados mostraram a inexistência de correlação entre o MVA e o EVA para empresas brasileiras no período analisado. 
Cerqueira, Soares e David (2009) também analisaram a existência de relação entre as métricas EVA e MVA para as empresas brasileiras de capital aberto. No estudo, havia a consideração preliminar de que, se uma empresa gerou elevados valores de EVA no passado, é de se esperar que essa informação seja considerada no valor de suas ações, o que seria refletido no seu MVA atual e futuro. A metodologia usada neste estudo consistiu da aplicação de modelos de regressão múltipla utilizando dados em painel. A amostra reuniu 26 empresas brasileiras listadas no Ibovespa, abrangendo os anos de 1998 a 2005. As relações encontradas indicaram que, no Brasil, o mercado acionário reage bem à geração de valor das empresas, conforme as expectativas iniciais.

Uma investigação interessante sobre a relação entre a medida MVA e o nível de liquidez corporativa foi feita no estudo de Coscarelli, Lamounier e Amaral (2011). No estudo, foram utilizados dados das empresas abertas que compunham a carteira do Índice de Sustentabilidade Empresarial (ISE) negociado na BM\&FBovespa, principal bolsa de valores do Brasil, no período de 2003 a 2008. A liquidez corporativa foi representada por um indicador denominado, no estudo, de Nível de Ativo Líquido (NAL), que é expresso como uma razão entre a conta Disponível, do Ativo, e o Ativo Total. Com abordagens em corte transversal e dados em painel, os resultados obtidos mostraram quase nenhuma consistência estatística na relação entre o MVA e o NAL. Os autores concluíram que as expectativas dos investidores com relação ao desempenho futuro do MVA das empresas não exerce influência sobre a liquidez corporativa.

A síntese dos estudos apresentados revela que não há consenso tanto sobre a relação significativa entre EVA e MVA, quanto dessas medidas com outras de desempenho financeiro. $\mathrm{O}$ que parece ser um ponto de aceitação pacífica é que o EVA deve ser uma medida superior aos indicadores contábeis convencionais uma vez que considera o custo total de capital investido e possibilita a avaliação relativa do desempenho corporativo em relação a esse custo, além de ser de fácil compreensão pelos diferentes tipos de stakeholders presentes nas organizações com fins lucrativos.

Com o presente estudo pretendemos contribuir para o aprimoramento das investigações nesse tema com a análise de um grupo de empresas de um setor específico (sucroalcooleiro) em um mercado local (Brasil).

\section{Metodologia da Pesquisa}

Esta é uma pesquisa classificada, segundo Lakatos e Marconi (1991), como quantitativa, conclusiva, descritiva, longitudinal e indutivista. Trata-se de uma pesquisa quantitativa e conclusiva por se apoiar em mensurações específicas, que são tratadas por procedimentos matemáticos, cujos resultados conduzem a uma conclusão acerca de um fenômeno ou relação. As pesquisas conclusivas podem ser descritivas ou causais. Trata-se aqui de uma pesquisa descritiva pela pretensão de mostrar a existência de uma relação entre variáveis, com procedimentos pré-planejados e estruturados, sem, contudo, pretender detectar uma relação de causalidade. As pesquisas descritivas podem ser transversais ou longitudinais. Este estudo se caracteriza como uma pesquisa longitudinal, uma vez que as amostras permanecem as mesmas ao longo do tempo, tendo somente seus valores sofrendo alterações. Trata-se também, de acordo com Martins (1995), de uma pesquisa indutivista, pois é estabelecida uma relação entre as variáveis que, extraída da amostra, pode ser generalizada 
para a população e o futuro pode ser interpretado como sendo, de algum modo, uma consequência do passado.

Os dados para este estudo são classificados como secundários, pois já foram coletados para objetivos que não os do problema em pauta. Para a realização dos testes empíricos, foram coletadas as informações contábeis de quatro empresas listadas na B\&MFBovespa, duas delas pertencentes a um mesmo grupo (Cosan). São elas: São Martinho S.A.; Cosan S.A. Indústria e Comércio; Cosan Limited; e Açúcar Guarani S.A. As séries históricas de cotações trimestrais das ações ordinárias das empresas são referentes ao período compreendido entre setembro de 2007 a junho de 2010. Além dessas quatro, havia, na data da realização deste estudo, apenas mais uma empresa sucroalcooleira listada na bolsa de valores brasileira, a Usina Costa Pinto S.A. Açúcar e Álcool, que foi excluída da amostra pela baixíssima liquidez de suas ações no mercado. Essas cinco empresas constituem-se na população das empresas do setor sucroalcooleiro listadas na BM\&FBovespa. Somente a partir de 2007, as quatro empresas consideradas neste estudo passaram a ter ações negociadas em pregão, o que limita a disponibilidade de dados. Uma observação a ser destacada é que, para o caso da Cosan Limited, os papéis considerados são units, ou seja, ativos compostos por mais de uma classe de valores mobiliários, representados por um certificado de depósito de ações, como um conjunto de ativos que pode ser formado por ações ordinárias, preferenciais, bônus de subscrição, entre outras, sempre negociadas em conjunto.

Foi feita uma análise não paramétrica de Correlação de Spearman sobre os dados. A hipótese testada sob o nível de significância estatística de 5\%, para cada uma das empresas, e a hipótese alternativa, são as que se seguem:

$\mathrm{H}_{0}$ : O coeficiente de correlação entre EVA e MVA é igual a zero $(\rho=0)$.

$\mathrm{H}_{1}$ : O coeficiente de correlação entre EVA e MVA não é igual a zero $(\rho \neq 0)$.

Os valores de EVA e MVA foram calculados para cada uma das quatro empresas da amostra com dados de cada um dos doze trimestres considerados no período. Os demonstrativos contábeis e do custo de capital foram obtidos no banco de dados Economática e nos sites da Comissão de Valores Mobiliários (CVM, 2010) e da Bolsa de Valores de São Paulo (BOVESPA, 2010).

Foi aplicado o modelo CAPM (SHARPE, 1964) para o cálculo do custo de capital próprio. A taxa livre de risco $\left(\mathrm{R}_{\mathrm{F}}\right)$ considerada $(5,46 \%$ a.a.) foi baseada na média aritmética do retorno mensal dos T-Bonds, dos EUA, no período de janeiro de 1990 a setembro de 2010. $\mathrm{O}$ retorno de mercado $\left(\mathrm{R}_{\mathrm{M}}\right)$ foi obtido $(7,46 \%$ a.a.) com base na média do retorno anual do mercado acionário (S\&P500) no mesmo período. O coeficiente beta (B) de cada empresa foi determinado calculando-se o quociente entre a covariância do retorno do índice S\&P500 com o retorno da ação de cada uma das empresas e a variância do retorno do mercado. Cada coeficiente beta foi ajustado pelo grau de alavancagem financeira de cada empresa. $O$ custo de capital de terceiros $\left(\mathrm{K}_{\mathrm{e}}\right)$ de cada empresa foi calculado com base nas informações contidas nas notas explicativas que acompanham a publicação trimestral dos Demonstrativos Contábeis das empresas de capital aberto analisadas. A expressão do modelo CAPM empregada foi:

$$
K_{e}=R_{F}+\beta \cdot\left(R_{M}-R_{F}\right)
$$

Os EVAs foram calculados com base na expressão: 


$$
\text { EVA }=\text { NOPAT }- \text { Capital Investido } * \text { WACC }
$$

Os resultados operacionais (NOPAT) e os capitais investidos foram obtidos pela reorganização das demonstrações contábeis das empresas em cada trimestre. Foi adotada a alíquota de $34 \%$ para o Imposto de Renda mais a Contribuição Social.

O WACC foi calculado como uma média ponderada entre os custos dos capitais de terceiros e próprio, conforme a equação:

Onde:

$$
W A C C=K_{d} \cdot R_{d}+K_{\varepsilon} \cdot R_{B}
$$

$K_{d}:$ Custo do capital de terceiros;

$R_{d}:$ Proporção de capital de terceiros no capital total da empresa;

$K_{g}$ : Custo do capital próprio;

$R_{B}$ : Proporção de capital próprio no capital total da empresa.

Para o cálculo do MVA foi considerado como valor de mercado da empresa (valor de mercado do Patrimônio Líquido) o produto da quantidade de ações ordinárias (ou units, no caso da Cosan Limited) negociadas no mercado pelo preço de fechamento do último pregão de cada trimestre do período analisado, e do resultado foi subtraído o valor do capital próprio (Patrimônio Líquido) investido na empresa. O cálculo pode ser expresso pela equação:

$$
M V A=\text { Valor de Mercado }- \text { Patrimônio Líquido }
$$

(Equação 4)

\section{Apresentação e Análise dos Resultados}

As Tabelas 1 a 7, apresentadas a seguir, mostram os dados usados nos cálculos do EVA e do MVA trimestrais de cada empresa analisada e os resultados obtidos. A Tabela 1 mostra os dados trimestrais utilizados para se calcular o custo do capital próprio de cada uma das empresas, com o uso da Equação 1. Por exemplo, pode-se ver na tabela que, no terceiro trimestre de 2007, considerados os valores de $R_{M}=7,46 \%$ e $R_{F}=5,46 \%$ e um beta alavancado $\beta_{L}=1,078$, o custo do capital próprio da São Martinho foi calculado como

\begin{tabular}{|c|c|c|c|c|c|c|c|c|c|c|}
\hline \multirow[t]{2}{*}{ Trimestre } & \multirow[t]{2}{*}{$\mathbf{R}_{\mathbf{M}}$} & \multirow[t]{2}{*}{$\mathbf{R}_{\mathbf{F}}$} & \multicolumn{2}{|c|}{ São Martinho } & \multicolumn{2}{|c|}{ Cosan S.A. } & \multicolumn{2}{|c|}{ Cosan Limited } & \multicolumn{2}{|c|}{ Guarani } \\
\hline & & & $\boldsymbol{\beta}_{\mathrm{L}}$ & $\mathbf{K}_{\mathrm{e}}$ & $\boldsymbol{\beta}_{\mathrm{L}}$ & $\mathbf{K}_{\mathrm{e}}$ & $\boldsymbol{\beta}_{\mathrm{L}}$ & $\overline{K_{e}}$ & $\boldsymbol{\beta}_{\mathrm{L}}$ & $\mathbf{K}_{\mathrm{e}}$ \\
\hline $3 / 2007$ & $7,46 \%$ & $5,46 \%$ & 1,078 & $6,89 \%$ & 1,520 & $7,62 \%$ & 0,708 & $6,00 \%$ & 0,499 & $5,58 \%$ \\
\hline $4 / 2007$ & $7,46 \%$ & $5,46 \%$ & 1,086 & $6,44 \%$ & 1,188 & $6,37 \%$ & 0,708 & $5,41 \%$ & 0,518 & $5,03 \%$ \\
\hline $1 / 2008$ & $7,46 \%$ & $5,46 \%$ & 1,079 & $5,82 \%$ & 1,187 & $6,01 \%$ & 0,709 & $5,06 \%$ & 0,580 & $4,80 \%$ \\
\hline $2 / 2008$ & $7,46 \%$ & $5,46 \%$ & 1,084 & $6,05 \%$ & 1,167 & $6,33 \%$ & 0,709 & $5,41 \%$ & 0,590 & $5,18 \%$ \\
\hline $3 / 2008$ & $7,46 \%$ & $5,46 \%$ & 1,100 & $6,06 \%$ & 1,249 & $6,29 \%$ & 0,710 & $5,21 \%$ & 0,727 & $5,25 \%$ \\
\hline
\end{tabular}
$K_{8}=6,89 \% a \cdot a$.

Tabela 1 - Dados do cálculo do custo de capital próprio pelo método CAPM 
A Relação entre a Geração de Valor Econômico e o Valor de Mercado das Empresas Sucroalcooleiras...

\begin{tabular}{lllllllllll}
\hline $4 / 2008$ & $7,46 \%$ & $5,46 \%$ & 1,102 & $5,44 \%$ & 1,445 & $5,67 \%$ & 0,757 & $4,30 \%$ & 0,777 & $4,34 \%$ \\
$1 / 2009$ & $7,46 \%$ & $5,46 \%$ & 1,095 & $4,93 \%$ & 1,515 & $5,87 \%$ & 0,760 & $4,36 \%$ & 0,735 & $4,31 \%$ \\
$2 / 2009$ & $7,46 \%$ & $5,46 \%$ & 1,093 & $5,51 \%$ & 1,375 & $6,07 \%$ & 0,752 & $4,82 \%$ & 0,714 & $4,75 \%$ \\
$3 / 2009$ & $7,46 \%$ & $5,46 \%$ & 1,103 & $5,72 \%$ & 1,389 & $6,30 \%$ & 0,709 & $4,93 \%$ & 0,720 & $4,96 \%$ \\
$4 / 2009$ & $7,46 \%$ & $5,46 \%$ & 1,110 & $5,68 \%$ & 1,308 & $6,08 \%$ & 0,715 & $4,89 \%$ & 0,730 & $4,92 \%$ \\
$1 / 2010$ & $7,46 \%$ & $5,46 \%$ & 1,086 & $5,89 \%$ & 1,302 & $6,32 \%$ & 0,714 & $5,15 \%$ & 0,770 & $5,26 \%$ \\
$2 / 2010$ & $7,46 \%$ & $5,46 \%$ & 1,082 & $5,66 \%$ & 1,283 & $6,06 \%$ & 0,714 & $4,92 \%$ & 0,667 & $4,83 \%$ \\
\hline \hline
\end{tabular}

$\mathrm{R}_{\mathrm{M}}$ é a taxa de retorno de mercado $\quad \mathrm{R}_{\mathrm{F}}$ é a taxa de retorno livre de risco

$\beta_{\mathrm{L}}$ é o coeficiente beta alavancado $\quad \mathrm{K}_{\mathrm{e}}$ é a taxa de custo do capital de terceiros

Fonte: Dados da pesquisa.

As Tabelas 2 e 3 mostram os dados trimestrais utilizados para se calcular o custo médio ponderado de capital para cada uma das empresas com o uso da Equação 3. Por exemplo, pode-se ver na Tabela 2 que, no terceiro trimestre de 2007, considerados os valores de $R_{\theta}=85 \%, K_{\theta}=6.89 \%, R_{d}=15 \%$ e $K_{a}=8,42 \%$, o $W A C C=7,12 \%$ a a . é obtido para a São Martinho S.A.

Tabela 2 - Dados do cálculo do WACC da São Martinho S.A. e Cosan S.A.

\begin{tabular}{|c|c|c|c|c|c|c|c|c|c|c|}
\hline \multirow[b]{2}{*}{ Trimestre } & \multicolumn{5}{|c|}{ São Martinho S.A. } & \multicolumn{5}{|c|}{ Cosan S.A. } \\
\hline & $\mathbf{R}_{\mathbf{e}}$ & $\mathbf{K}_{\mathbf{e}}$ & $\mathbf{R}_{\mathbf{d}}$ & $\mathbf{K}_{\mathbf{i}}$ & WACC & $\mathbf{R}_{\mathbf{e}}$ & $\mathbf{K}_{\mathbf{e}}$ & $\mathbf{R}_{\mathbf{d}}$ & $\mathbf{K}_{\mathbf{i}}$ & WACC \\
\hline $3 / 2007$ & $85 \%$ & $6,89 \%$ & $15 \%$ & $8,42 \%$ & $7,12 \%$ & $42 \%$ & $7,62 \%$ & $58 \%$ & $7,87 \%$ & $7,76 \%$ \\
\hline $4 / 2007$ & $85 \%$ & $6,44 \%$ & $15 \%$ & $8,42 \%$ & $6,74 \%$ & $61 \%$ & $6,37 \%$ & $39 \%$ & $7,86 \%$ & $6,95 \%$ \\
\hline $1 / 2008$ & $86 \%$ & $5,82 \%$ & $14 \%$ & $7,79 \%$ & $6,10 \%$ & $61 \%$ & $6,01 \%$ & $39 \%$ & $7,83 \%$ & $6,72 \%$ \\
\hline $2 / 2008$ & $85 \%$ & $6,05 \%$ & $15 \%$ & $7,79 \%$ & $6,32 \%$ & $61 \%$ & $6,33 \%$ & $39 \%$ & $7,74 \%$ & $6,88 \%$ \\
\hline $3 / 2008$ & $83 \%$ & $6,06 \%$ & $17 \%$ & $7,79 \%$ & $6,36 \%$ & $56 \%$ & $6,29 \%$ & $44 \%$ & $7,74 \%$ & $6,93 \%$ \\
\hline $4 / 2008$ & $83 \%$ & $5,44 \%$ & $17 \%$ & $7,79 \%$ & $5,85 \%$ & $48 \%$ & $5,67 \%$ & $52 \%$ & $5,73 \%$ & $5,70 \%$ \\
\hline $1 / 2009$ & $83 \%$ & $4,93 \%$ & $17 \%$ & $23,35 \%$ & $7,99 \%$ & $45 \%$ & $5,87 \%$ & $55 \%$ & $5,73 \%$ & $5,79 \%$ \\
\hline $2 / 2009$ & $83 \%$ & $5,51 \%$ & $17 \%$ & $23,35 \%$ & $8,47 \%$ & $50 \%$ & $6,07 \%$ & $50 \%$ & $5,51 \%$ & $5,79 \%$ \\
\hline $3 / 2009$ & $82 \%$ & $5,72 \%$ & $18 \%$ & $23,35 \%$ & $8,85 \%$ & $50 \%$ & $6,30 \%$ & $50 \%$ & $5,32 \%$ & $5,81 \%$ \\
\hline $4 / 2009$ & $82 \%$ & $5,68 \%$ & $18 \%$ & $23,35 \%$ & $8,91 \%$ & $55 \%$ & $6,08 \%$ & $45 \%$ & $6,28 \%$ & $6,17 \%$ \\
\hline $1 / 2010$ & $84 \%$ & $5,89 \%$ & $16 \%$ & $30,18 \%$ & $9,76 \%$ & $50 \%$ & $6,32 \%$ & $45 \%$ & $14,77 \%$ & $10,13 \%$ \\
\hline $2 / 2010$ & $84 \%$ & $5,66 \%$ & $16 \%$ & $30,18 \%$ & $9,51 \%$ & $56 \%$ & $6,06 \%$ & $44 \%$ & $16,22 \%$ & $10,56 \%$ \\
\hline
\end{tabular}

$\mathrm{R}_{\mathrm{e}}$ é o percentual de capital próprio na empresa $\quad \mathrm{R}_{\mathrm{d}}$ é o percentual de capital de terceiros na empresa

$\mathrm{K}_{\mathrm{e}}$ é a taxa de custo do capital próprio $\quad \mathrm{K}_{\mathrm{i}}$ é a taxa de custo do capital de terceiros

WACC é a taxa de custo médio ponderado de capital

Fonte: Dados da pesquisa.

Tabela 3 - Dados do cálculo do WACC da Cosan Limited e Guarani S.A.

\begin{tabular}{|c|c|c|c|c|c|c|c|c|c|c|}
\hline & \multicolumn{5}{|c|}{ Cosan Limited } & \multicolumn{5}{|c|}{ Guarani S.A. } \\
\hline Trimestre & $\mathbf{R}_{\mathrm{e}}$ & $\mathbf{K}_{\mathrm{e}}$ & $\overline{\mathbf{R}_{\mathrm{d}}}$ & $\mathbf{K}_{\mathbf{i}}$ & WACC & $\mathbf{R}_{\mathrm{e}}$ & $\mathbf{K}_{\mathrm{e}}$ & $\overline{\mathbf{R}_{\mathrm{d}}}$ & $\mathbf{K}_{\mathbf{i}}$ & WACC \\
\hline $3 / 2007$ & $100 \%$ & $6,00 \%$ & $0 \%$ & $6,85 \%$ & $6,00 \%$ & $80 \%$ & $5,58 \%$ & $20 \%$ & $6,73 \%$ & $5,81 \%$ \\
\hline $4 / 2007$ & $100 \%$ & $5,41 \%$ & $0 \%$ & $6,82 \%$ & $5,41 \%$ & $77 \%$ & $5,03 \%$ & $23 \%$ & $4,82 \%$ & $4,98 \%$ \\
\hline $1 / 2008$ & $100 \%$ & $5,06 \%$ & $0 \%$ & $6,78 \%$ & $5,06 \%$ & $67 \%$ & $4,80 \%$ & $33 \%$ & $8,04 \%$ & $5,88 \%$ \\
\hline $2 / 2008$ & $100 \%$ & $5,41 \%$ & $0 \%$ & $6,68 \%$ & $5,41 \%$ & $64 \%$ & $5,18 \%$ & $36 \%$ & $8,03 \%$ & $6,20 \%$ \\
\hline $3 / 2008$ & $100 \%$ & $5,21 \%$ & $0 \%$ & $6,56 \%$ & $5,22 \%$ & $48 \%$ & $5,25 \%$ & $52 \%$ & $9,21 \%$ & $7,31 \%$ \\
\hline $4 / 2008$ & $91 \%$ & $4,30 \%$ & $9 \%$ & $6,13 \%$ & $4,47 \%$ & $45 \%$ & $4,34 \%$ & $55 \%$ & $8,17 \%$ & $6,44 \%$ \\
\hline $1 / 2009$ & $90 \%$ & $4,36 \%$ & $10 \%$ & $6,10 \%$ & $4,53 \%$ & $48 \%$ & $4,31 \%$ & $52 \%$ & $6,28 \%$ & $5,33 \%$ \\
\hline
\end{tabular}

113 ISSN 2175-8069, UFSC, Florianópolis, v.9, n.17, p. 103-120, jan./jun., 2012 
Melise Alessandra Sobue e Tabajara Pimenta Junior

\begin{tabular}{|c|ccccc|ccccc|}
\hline $2 / 2009$ & $92 \%$ & $4,82 \%$ & $8 \%$ & $5,51 \%$ & $4,88 \%$ & $50 \%$ & $4,75 \%$ & $50 \%$ & $6,10 \%$ & $5,42 \%$ \\
$3 / 2009$ & $100 \%$ & $4,93 \%$ & $0 \%$ & $5,40 \%$ & $4,93 \%$ & $48 \%$ & $4,96 \%$ & $52 \%$ & $6,45 \%$ & $5,73 \%$ \\
$4 / 2009$ & $99 \%$ & $4,89 \%$ & $1 \%$ & $5,86 \%$ & $4,91 \%$ & $48 \%$ & $4,92 \%$ & $52 \%$ & $7,03 \%$ & $6,03 \%$ \\
$1 / 2010$ & $99 \%$ & $5,15 \%$ & $1 \%$ & $5,50 \%$ & $5,15 \%$ & $45 \%$ & $5,26 \%$ & $55 \%$ & $8,52 \%$ & $7,04 \%$ \\
$2 / 2010$ & $99 \%$ & $4,92 \%$ & $1 \%$ & $9,93 \%$ & $4,98 \%$ & $55 \%$ & $4,83 \%$ & $45 \%$ & $24,6 \%$ & $13,82 \%$ \\
\hline \hline
\end{tabular}

$\mathrm{R}_{\mathrm{e}}$ é o percentual de capital próprio na empresa $\quad \mathrm{R}_{\mathrm{d}}$ é o percentual de capital de terceiros na empresa

$\mathrm{K}_{\mathrm{e}}$ é a taxa de custo do capital próprio $\quad \mathrm{K}_{\mathrm{i}}$ é a taxa de custo do capital de terceiros

WACC é a taxa de custo médio ponderado de capital

Fonte: Dados da pesquisa.

As Tabelas 4 e 5 mostram os dados trimestrais utilizados para se calcular o EVA para cada uma das empresas com o uso da Equação 2. Por exemplo, pode-se ver na Tabela 4, que no terceiro trimestre de 2007, considerados os valores de NOPAT $=-\boldsymbol{R} \$ 62.058 .000$, Capital Investido $=R \$ 818.286 .000$ e $W A C C=7,12 \%$, um $E V A=-R \$ 120.298 .000$ foi obtido para a São Martinho S.A.

Tabela 4 - Dados do cálculo do EVA da São Martinho S.A. e Cosan S.A.

\begin{tabular}{|c|c|c|c|c|c|c|c|c|}
\hline \multirow[b]{2}{*}{ Trimestre } & \multicolumn{4}{|c|}{ São Martinho S.A. } & \multicolumn{4}{|c|}{ Cosan S.A. } \\
\hline & $\begin{array}{l}\text { NOPAT } \\
\text { [R\$ mil] }\end{array}$ & $\begin{array}{c}\text { Capital } \\
\text { Investido } \\
{[\mathbf{R} \$ \text { mil }]}\end{array}$ & $\begin{array}{l}\text { WACC } \\
\text { [\%a.a.] }\end{array}$ & $\begin{array}{c}\text { EVA } \\
{[\text { R\$ mil }]}\end{array}$ & $\begin{array}{l}\text { NOPAT } \\
\text { [R\$ mil] }\end{array}$ & $\begin{array}{c}\text { Capital } \\
\text { Investido } \\
{[\mathrm{R} \$ \text { mil }]}\end{array}$ & $\begin{array}{l}\text { WACC } \\
\text { [\%a.a.] }\end{array}$ & $\begin{array}{c}\text { EVA } \\
{[\mathbf{R} \$ \text { mil] }}\end{array}$ \\
\hline $3 / 2007$ & -62.058 & 818.286 & $7,12 \%$ & -120.298 & -101.085 & 1.971 .815 & $7,76 \%$ & -254.151 \\
\hline $4 / 2007$ & -71.613 & 813.412 & $6,74 \%$ & -126.441 & -309.853 & 3.522 .438 & $6,95 \%$ & -555.717 \\
\hline $1 / 2008$ & -70.588 & 770.416 & $6,10 \%$ & -117.612 & -377.149 & 3.306 .515 & $6,72 \%$ & -599.432 \\
\hline $2 / 2008$ & -31.530 & 833.243 & $6,32 \%$ & -84.179 & -181.873 & 2.169 .398 & $6,88 \%$ & -331.055 \\
\hline $3 / 2008$ & -89.576 & 751.279 & $6,36 \%$ & -137.362 & -260.755 & 2.295 .512 & $6,93 \%$ & -419.754 \\
\hline $4 / 2008$ & -151.990 & 755.692 & $5,85 \%$ & -196.184 & -325.843 & 2.307.552 & $5,70 \%$ & -457.389 \\
\hline $1 / 2009$ & -98.121 & 749.440 & $7,99 \%$ & -157.971 & -264.739 & 2.055 .624 & $5,79 \%$ & -383.816 \\
\hline $2 / 2009$ & 7.885 & 750.427 & $8,47 \%$ & -55.686 & 510.877 & 1.753 .004 & $5,79 \%$ & 409.356 \\
\hline $3 / 2009$ & 18.276 & 774.969 & $8,85 \%$ & -50.324 & 594.717 & 1.506 .698 & $5,81 \%$ & 507.234 \\
\hline $4 / 2009$ & 33.573 & 758.361 & $8,91 \%$ & -34.001 & 623.186 & 1.859 .373 & $6,17 \%$ & 508.484 \\
\hline $1 / 2010$ & 50.399 & 773.400 & $9,76 \%$ & -25.114 & 863.829 & 1.907 .796 & $10,13 \%$ & 670.629 \\
\hline $2 / 2010$ & 16.978 & 762.785 & $9,51 \%$ & -55.553 & -25.967 & 1.686 .759 & $10,56 \%$ & -204.150 \\
\hline
\end{tabular}

Fonte: Dados da pesquisa.

Tabela 5 - Dados do cálculo do EVA da Cosan Limited e Guarani S.A.

\begin{tabular}{|c|c|c|c|c|c|c|c|c|}
\hline & \multicolumn{4}{|c|}{ Cosan Limited } & \multicolumn{4}{|c|}{ Guarani S.A. } \\
\hline Trimestre & $\begin{array}{l}\text { NOPAT } \\
\text { [R\$ mil] }\end{array}$ & $\begin{array}{c}\text { Capital } \\
\text { Investido } \\
\text { [R\$ mil] }\end{array}$ & $\begin{array}{c}\text { WACC } \\
\text { [\%a.a.] }\end{array}$ & $\begin{array}{c}\text { EVA } \\
{[\mathbf{R} \$ \text { mil }]}\end{array}$ & $\begin{array}{l}\text { NOPAT } \\
{[R \$ \text { mil }]}\end{array}$ & $\begin{array}{c}\text { Capital } \\
\text { Investido } \\
{[\mathrm{R} \$ \text { mil] }}\end{array}$ & $\begin{array}{c}\text { WACC } \\
\text { [\%a.a.] }\end{array}$ & $\begin{array}{c}\text { EVA } \\
{[\mathbf{R} \$ \text { mil }]}\end{array}$ \\
\hline $3 / 2007$ & -56.152 & 1.969 .939 & $6,00 \%$ & -174.254 & -31.486 & 584.673 & $5,81 \%$ & -65.462 \\
\hline $4 / 2007$ & -109.013 & 804.918 & $5,41 \%$ & -152.552 & -52.370 & 604.727 & $4,98 \%$ & -82.485 \\
\hline $1 / 2008$ & -50.848 & 816.665 & $5,06 \%$ & -92.173 & -61.732 & 1.007 .547 & $5,88 \%$ & -120.998 \\
\hline
\end{tabular}


A Relação entre a Geração de Valor Econômico e o Valor de Mercado das Empresas Sucroalcooleiras...

\begin{tabular}{|c|cccc|cccc|}
\hline $2 / 2008$ & -14.130 & 763.063 & $5,41 \%$ & -55.433 & -51.861 & 986.585 & $6,20 \%$ & -113.040 \\
$3 / 2008$ & -692.332 & 485.033 & $5,22 \%$ & -717.640 & -125.294 & 1.311 .396 & $7,31 \%$ & -221.116 \\
$4 / 2008$ & -779.822 & 880.038 & $4,47 \%$ & -819.133 & -147.722 & 1.336 .782 & $6,44 \%$ & -233.789 \\
$1 / 2009$ & -560.496 & 872.078 & $4,53 \%$ & -600.036 & -193.703 & 1.523 .876 & $5,33 \%$ & -274.858 \\
$2 / 2009$ & -21.885 & 736.320 & $4,88 \%$ & -57.834 & 39.661 & 1.425 .578 & $5,42 \%$ & -37.610 \\
$3 / 2009$ & 20.800 & 428.520 & $4,93 \%$ & -346 & 44.145 & 1.430 .784 & $5,73 \%$ & -37.797 \\
$4 / 2009$ & 80.359 & 49.098 & $4,91 \%$ & 77.951 & 40.064 & 1.453 .952 & $6,03 \%$ & -47.574 \\
$1 / 2010$ & 142.610 & 45.372 & $5,15 \%$ & 140.273 & 22.084 & 1.278 .909 & $7,04 \%$ & -67.987 \\
$2 / 2010$ & -3.153 & 40.915 & $4,98 \%$ & -5.191 & -47.111 & 1.176 .801 & $13,82 \%$ & -209.742 \\
\hline \hline
\end{tabular}

Fonte: Dados da pesquisa.

As Tabelas 6 e 7 mostram os dados trimestrais utilizados para se calcular o MVA para cada uma das empresas, com o uso da Equação 4. Por exemplo, pode-se ver na Tabela 6 que, no terceiro trimestre de 2007, considerados para a São Martinho o Valor de Mercado = R\$ 2.247 milhões e o Valor do $\mathrm{PL}=\mathrm{R} \$ 696$ milhões, obteve-se um MVA = R \$ 1.551 milhão.

Tabela 6 - Dados do cálculo do MVA da São Martinho S.A. e Cosan S.A.

\begin{tabular}{|c|ccc|ccc|}
\hline \hline & \multicolumn{3}{|c|}{ São Martinho S.A. } & \multicolumn{3}{c|}{ Cosan S.A. } \\
\hline \hline \multirow{2}{*}{ Trimestre } & $\begin{array}{c}\text { Valor de } \\
\text { Mercado } \\
\text { [R\$ Milhões] }\end{array}$ & $\begin{array}{c}\text { Valor do PL } \\
\text { [R\$ Milhões] }\end{array}$ & $\begin{array}{c}\text { MVA } \\
\text { [R\$ milhões] }\end{array}$ & $\begin{array}{c}\text { Valor de } \\
\text { Mercado } \\
\text { [R\$ Milhões] }\end{array}$ & $\begin{array}{c}\text { Valor do PL } \\
\text { [R\$ Milhões] }\end{array}$ & $\begin{array}{c}\text { MVA } \\
\text { [R milhões] }\end{array}$ \\
\hline $3 / 2007$ & 2.247 & 696 & 1.551 & 4.924 & 828 & 4.096 \\
$4 / 2007$ & 2.242 & 691 & 1.551 & 7.186 & 2.149 & 5.037 \\
$1 / 2008$ & 2.887 & 663 & 2.224 & 7.816 & 2.017 & 5.799 \\
$2 / 2008$ & 2.874 & 708 & 2.166 & 8.048 & 1.323 & 6.725 \\
$3 / 2008$ & 2.048 & 624 & 1.424 & 3.388 & 1.285 & 2.103 \\
$4 / 2008$ & 1.017 & 627 & 390 & 3.372 & 1.108 & 2.264 \\
$1 / 2009$ & 1.276 & 622 & 654 & 3.102 & 925 & 2.177 \\
$2 / 2009$ & 1.831 & 623 & 1.208 & 5.260 & 877 & 4.383 \\
$3 / 2009$ & 1.842 & 635 & 1.207 & 7.149 & 753 & 6.396 \\
$4 / 2009$ & 1.905 & 622 & 1.283 & 10.203 & 1.023 & 9.180 \\
$1 / 2010$ & 1.825 & 650 & 1.175 & 8.641 & 954 & 7.687 \\
$2 / 2010$ & 1.563 & 641 & 922 & 9.000 & 945 & 8.055 \\
\hline \hline
\end{tabular}

Fonte: Dados da pesquisa.

Tabela 7 - Dados do cálculo do MVA da Cosan Limited e Guarani S.A.

\begin{tabular}{|c|ccc|ccc|}
\hline \hline & \multicolumn{3}{|c|}{ Cosan Limited } & \multicolumn{3}{c|}{ Guarani S.A. } \\
\hline \hline \multirow{3}{*}{ Trimestre } & $\begin{array}{c}\text { Valor de } \\
\text { Mercado } \\
\text { [R\$ Milhões] }\end{array}$ & $\begin{array}{c}\text { Valor do PL } \\
\text { [R\$ Milhões] }\end{array}$ & $\begin{array}{c}\text { MVA } \\
\text { [R\$ milhões] }\end{array}$ & $\begin{array}{c}\text { Valor de } \\
\text { Mercado } \\
\text { [R\$ Milhões] }\end{array}$ & $\begin{array}{c}\text { Valor do PL } \\
\text { [R\$ Milhões] }\end{array}$ & $\begin{array}{c}\text { MVA } \\
\text { [R milhões] }\end{array}$ \\
\hline $3 / 2007$ & 4.461 & 1.970 & 2.491 & 1.652 & 468 & 1.184 \\
$4 / 2007$ & 5.094 & 805 & 4.289 & 1.768 & 466 & 1.302 \\
$1 / 2008$ & 4.945 & 817 & 4.128 & 1.593 & 675 & 918 \\
\hline
\end{tabular}

115 ISSN 2175-8069, UFSC, Florianópolis, v.9, n.17, p. 103-120, jan./jun., 2012 
Melise Alessandra Sobue e Tabajara Pimenta Junior

\begin{tabular}{|l|llc|ccc|}
\hline $2 / 2008$ & 4.708 & 763 & 3.945 & 1.447 & 631 & 816 \\
$3 / 2008$ & 1.611 & 485 & 1.126 & 383 & 629 & -246 \\
$4 / 2008$ & 2.044 & 801 & 1.243 & 343 & 602 & -259 \\
$1 / 2009$ & 1.492 & 785 & 707 & 536 & 731 & -195 \\
$2 / 2009$ & 2.675 & 677 & 1.998 & 1.224 & 713 & 511 \\
$3 / 2009$ & 3.861 & 429 & 3.432 & 1.683 & 687 & 996 \\
$4 / 2009$ & 4.033 & 49 & 3.984 & 1.606 & 698 & 908 \\
$1 / 2010$ & 4.463 & 45 & 4.418 & 1.336 & 576 & 760 \\
$2 / 2010$ & 4.479 & 41 & 4.438 & 1.090 & 647 & 443 \\
\hline \hline
\end{tabular}

Fonte: Dados da pesquisa.

A realização da análise de Correlação de Spearman gerou o resultado exposto na Tabela 8.

Tabela 8 - Análise da Correlação de Spearman entre EVA e MVA das Empresas

\begin{tabular}{|c|c|c|c|c|}
\hline & São Martinho & Cosan S.A. & Cosan Limited & Guarani \\
\hline Correlação entre EVA e MVA & 0,26 & 0,55 & 0,83 & 0,83 \\
\hline Significância Estatística* & 0,4151 & 0,0648 & 0,0008 & 0,0007 \\
\hline
\end{tabular}

*crítica ao nível de $5 \%$

Fonte: Dados da pesquisa.

Os resultados obtidos indicam, conforme os dados da Tabela 8, que se observaram correlações positivas significativas $(\rho=0,83)$ entre os valores de EVA e MVA para as empresas Cosan Limited e Guarani, ao nível de significância de 5\%. Para as outras duas empresas, o resultado mostrou correlações não significativas estatisticamente entre as variáveis de desempenho econômico, ao nível de 5\% de significância, muito embora, para ambos os casos, a correlação calculada tenha sido positiva.

Uma consideração interessante a respeito da inexistência de correlação entre essas variáveis vem de Stewart (2005, p. 185), ao afirmar que

\begin{abstract}
Até que o EVA se torne positivo, os valores de mercado estão desconectados, com efeito, das medidas internas de performance. Isso porque o potencial para liquidação, recuperação, reestruturação financeira ou tomada de controle hostil, determinam um piso para o valor de mercado. Mas uma vez que o EVA se torne positivo, há uma alta correlação entre o nível do EVA e o nível do valor de mercado agregado.
\end{abstract}

Para Stewart (2005), a correlação entre EVA e MVA deveria existir e ser positiva, mas quando há a geração de EVA (EVAs positivos). Os dados das empresas aqui analisados mostram uma predominância de EVAs trimestrais negativos, o que pode contribuir para explicar a fraca correlação entre as duas variáveis para as empresas São Martinho e Cosan, mas não para explicar a existência de correlações significativas para as outras duas empresas.

Outra consideração a ser feita é que as análises de correlação compararam o EVA médio de um determinado período com o MVA final desse mesmo período. Segundo Santos e Watanabe (2005), o raciocínio implícito é que, caso uma empresa apresente uma melhora no 
EVA apurado em um determinado período e o mercado acredite que essa melhora vai perdurar no futuro, então esse acréscimo de desempenho deverá se refletir no seu MVA.

Para as empresas analisadas, observa-se que o EVA é, na sua maioria, negativo e o MVA positivo. Como citado anteriormente, o EVA reflete o desempenho passado da empresa, já o MVA incorpora a expectativa de resultados futuros. Isso significa que, mesmo tendo hoje um desempenho negativo na geração de EVA, uma empresa pode apresentar MVA positivo se a expectativa dos investidores for de um desempenho positivo do EVA no futuro.

A São Martinho S.A., por exemplo, não apresentou EVA positivo em nenhum dos trimestres do período analisado (de setembro de 2007 a junho de 2010), e, no entanto, mostra MVA positivo em todos os trimestres.

Para avaliar se as correlações poderiam ser afetadas pela demora do mercado em perceber a criação de valor, outra análise foi feita, dessa vez com uma defasagem de um trimestre. Cada valor de EVA foi alinhado com o valor do MVA referente ao trimestre posterior. O principal objetivo dessa nova análise foi o de verificar se o mercado demora em reagir às informações trimestrais de agregação de valor.

A Tabela 9 exibe os resultados encontrados.

Tabela 9 - Análise da Correlação entre EVA e MVA com Defasagem de um Trimestre

\begin{tabular}{|c|c|c|c|c|}
\hline & São Martinho & Cosan S.A. & Cosan Limited & Guarani \\
\hline Correlação entre EVA e MVA & $-0,12$ & 0,30 & 0,46 & 0,37 \\
\hline Significância Estatística* & 0,7234 & 0,3758 & 0,1552 & 0,2575 \\
\hline
\end{tabular}

*crítica ao nível de $5 \%$

Fonte: Dados da pesquisa.

Essa segunda análise revelou não existirem correlações estatisticamente significativas entre a geração de EVA e o MVA para todas as quatro empresas analisadas. Os resultados sugerem indícios da existência de uma correlação contemporânea entre esses dois indicadores de desempenho econômico, mas não com defasagem temporal. Uma possibilidade de explicação para o fenômeno é a maior velocidade com que as novas informações são atualmente precificadas pelo mercado, inclusive levando-se em consideração os movimentos do mercado em função da antecipação (expectativas) da divulgação das informações contábeis e financeiras das empresas.

\section{Considerações Finais}

Este estudo foi desenvolvido sobre quatro empresas do setor sucroalcooleiro (de um total de cinco empresas listadas na BM\&FBovespa) para investigar se existe correlação entre a geração de valor econômico, medido pelo EVA, e o valor econômico adicionado a mercado, medido pelo MVA. Os resultados revelaram a existência de correlações fortes $(\rho=0,83)$ e estatisticamente significativas (ao nível de 5\%) para os indicadores de duas das empresas (Cosan Limited e Guarani) e de correlações sem significância estatística para os das outras duas (São Martinho e Cosan). Assim, não se obteve um resultado que possa ser considerado

117 ISSN 2175-8069, UFSC, Florianópolis, v.9, n.17, p. 103-120, jan./jun., 2012 
conclusivo no que tange à existência de correlação entre EVA e MVA das empresas de capital aberto do setor sucroalcooleiro brasileiro.

As correlações relevantes entre EVA e MVA, obtidas para duas das empresas, é um resultado inovador em relação aos obtidos por Saurin, Mussi e Cordioli (2000), que não indicaram qualquer relação expressiva entre essas duas medidas de desempenho econômico. Uma razão para a diferença de resultados pode estar no fato de que o estudo feito em 2000 explorou dados de empresas que passaram por processos de privatização, o que pode ter prejudicado temporariamente a percepção dos investidores acerca do desempenho futuro daquelas companhias.

Os resultados aqui alcançados também diferem dos obtidos por Santos e Watanabe (2005), uma vez que, naquele estudo, foi detectada a inexistência de correlação entre o MVA e o EVA para empresas brasileiras de capital aberto, analisados os dados do período de 1996 a 2001.

Outro resultado interessante foi a obtenção de correlações significativas considerandose EVA e MVA contemporâneos, e a ausência de correlações estatisticamente significativas quando os dados foram tratados com uma defasagem de um trimestre. A literatura científica sobre esse tema mostra que é esperado que a divulgação da geração de EVA em um dado período seja refletida como uma variação do MVA em um período posterior, uma vez que é necessário algum tempo para que as expectativas dos investidores, acerca do futuro da empresa, absorvam adequadamente a informação. Informações sobre desempenho econômico são, conforme estabelece Stewart (2005) e Copeland (2002), menos observadas e mais lentamente consideradas pelos investidores, do que informações sobre indicadores convencionais de desempenho empresarial. Por isso, o resultado aqui obtido que mostra uma relação consistente entre EVA e MVA contemporâneos, e não entre medidas defasadas, é uma inovação no tema.

Naturalmente, os resultados obtidos com este estudo, bem como as conclusões e considerações geradas, não podem ser extrapolados para outras empresas, outros períodos temporais ou para outros setores de atividade. Este estudo teve duas limitações importantes: uma referente ao pequeno número de empresas, muito embora represente $80 \%$ (quatro em cinco) das empresas abertas existentes no setor sucroalcooleiro brasileiro; e outra referente ao tamanho da série temporal dos dados (informações contábeis trimestrais de 2007 a 2010), uma vez que no passado recente não havia empresas desse setor listadas em bolsa no Brasil.

A revisão da literatura empreendida neste estudo não revelou artigos, além dos de Saurin, Mussi e Cordioli (2000) e de Santos e Watanabe (2005), que tivessem explorado a relação entre a geração de EVA e MVA para empresas abertas, em especial para empresas do setor sucroalcooleiro brasileiro. Por essa razão, é uma sugestão interessante que novos estudos sejam feitos para explorar essa relação no âmbito geral das companhias brasileiras, ou mesmo para setores específicos, como o da construção civil, o elétrico, o de mineração, o financeiro, dentre outros. Os resultados podem contribuir para ampliar o conhecimento existente sobre a questão do motivo pelo qual a ligação entre EVA e MVA parece ser menos consistente do que prevê a teoria.

\section{Referências}

BAUM, C. L.; SARVER, L.; STRICKLAND, T. EVA, MVA and CEO compensation: further evidence. American Business Review, vol. 22, n. 2, p. 82-87, 2004. 
BOVESPA. Disponível em: <http://www.bovespa.com.br> Acesso em: 31 maio 2010.

CERQUEIRA, J. E. A.; SOARES, T. M.; DAVID, M. V. Novas evidências sobre a relação entre a geração de valor ao acionista e o valor de mercado das ações: uma análise em painel comparando o EVA e o MVA no mercado brasileiro. Pesquisa Operacional para o Desenvolvimento, vol. 2, n. 2, p. 178-196, 2009.

COPELAND, T.; KOLLER, T.; MURRIN J. Avaliação de empresas: calculando e gerenciando o valor das empresas. 3. ed. São Paulo: Makron Books, 2002.

COSCARELLI, B. V; LAMOUNIER, W. M; AMARAL, H. F. Liquidez corporative e o market value added. Advances in Scientific and Applied Accounting, v. 4, n. 3, p. 304-330, 2011.

CVM - Comissão de Valores Mobiliários. Disponível em:<http://www.cvm.gov.br/ indexpo.asp >. Acesso em 11 out. 2010.

FERGUSON, R.; RENTZLER J.; YU, S. Trading strategy on EVA and MVA: are they reliable indicators of future stock performance? Journal of Investing, v. 15, n. 4, p. 88-94, 2006.

FERREIRA, A. P.; LOPES, L. N. Indicadores contábeis X EVA: um estudo setorial. In: Congresso USP de Controladoria e Contabilidade, 5., São Paulo. Anais... São Paulo: USP, 2005. Disponível em:

<http://www.congressousp.fipecafi.org/artigos52005/an_resumo.asp?cod_trabalho=410> Acesso em 26 de abril de 2010.

COSAN. Disponível em:

$<$ http://www.cosan.com.br/cosan2009/web/conteudo_pt.asp?tipo=26366\&idioma=0\&conta=2 8\#anchor1>. Acesso em 26 de abril de 2010.

EHRBAR, A. EVA valor econômico agregado. Rio de Janeiro: Qualitymark, 1999.

KRAMER, J. K.; PUSHNER, G. An Empirical Analysis of Economic Value Added as a Proxy for Market Value Added. Financial Practice and Education, Spring/Summer, p. 4149, 1997.

KUMAR, S; SHARMA, A. K. Association of EVA and accounting earnings with market value: evidence from India. Asia-Pacific journal of business administration, v. 3, n. 2, p. 83-96, 2011.

LAKATOS, E.M; MARCONI, M. de A. Fundamentos de metodologia científica. 3. ed. São Paulo: Atlas, 1991.

MANDILAS, A.; FLOROPOULOS, I.; PIPILIAGKOPOULOS, M.; ANGELAKIS, G. EVA Reconsidered for the greek capital market. European Research Studies, v. 12, p. 37-54, 2009.

MARTINS, G. A. Manual para elaboração de monografias e dissertações. São Paulo: Atlas, 1995.

MITTAL, R. K.; SINHA, N.; SINGH, A. An analysis of linkage between economic value added and corporate social responsibility. Management Decision, v. 46, n. 9, p. 1437-1443, 2008 . 
MAPA - Ministério da Agricultura, Pecuária e Abastecimento. Relatório sobre o programa para produção e uso de biocombustíveis no mundo. Secretaria de Produção e Agroenergia - Departamento da Cana-de-açúcar e Agroenergia, 2009. Disponível em:

<http://www.agricultura.gov.br/pls/portal/docs/page/mapa/menu_lateral/agricultura_pecuaria/ cana_de_acucar_agroenergia/servi\%c7os/biocombustiveis\%20diversos\%20pa\%cdses_0_0_0. pdf> Acesso em: 21 de maio de 2010.

SANTOS, J. O.; WATANABE, R. Uma análise da correlação entre o EVA e o MVA no contexto das empresas brasileiras de capital aberto. Caderno de Pesquisas em Administração, vol. 12, n. 1, p. 19-32, 2005.

SAURIN, V.; MUSSI, C. C.; CORDIOLI, C. A. Estudo do desempenho econômico das empresas estatais privatizadas com base no MVA e EVA. Caderno de Pesquisas em Administração, vol. 12, n. 11, p. 18-26, 2000.

SHARPE, W. F. Capital Asset Prices: A theory of market equilibrium under conditions of risk. The Journal of Finance, vol. 19, n. 3, p. 425-442, 1964.

SILVEIRA, A. D. M.; OKIMURA, R. T.; SOUSA, A. F. O valor econômico adicionado (EVA) possui maior relação com o retorno das ações do que o lucro líquido no Brasil? In: SEMEAD - Seminários em Administração, 7., 2004, São Paulo. Anais... São Paulo: USP, 2004, p. 1-14.

STEWART, G. B. Em busca do valor: o guia de EVA para estrategistas. Porto Alegre: Bookman, 2005.

TURVEY, C. G.; LAKE, L.; DUREN, E. V.; SPARLING, D. The relationship between economic value added and the stock market performance of agribusiness firms. Agribusiness Hoboken, vol. 16, n. 4, p. 399-416, 2000. 